\title{
Panorama actual de la calidad normativa en el ordenamiento tras la aprobación de la Ley 39/2015
}

\author{
Iker Nabaskues Martínez de Eulate
}

DOI: https://doi.org/10.47623/ivap-rvap.109.2017.1.12

\begin{abstract}
Sumario: I. Introducción. - II. Problemas en torno a la calidad del ordenamiento.-III. Criterios generales para afrontar la calidad de las normas. -IV. Normativa aplicable respecto a la calidad de las normas: 1. Marco normativo europeo a partir de 2016. 2. Marco normativo en el Estado. 2.1. La calidad de las normas tras la Ley 39/2015 LPACAP. 2.1.1. Novedades en la Ley 39/2015 que sistematizan la buena regulación en el procedimiento de elaboración de normas: los principios de buena regulación. 2.1.2. Novedades en la Ley 39/2015 que incentivan la participación ciudadana en el procedimiento de elaboración de normas: a) La consulta previa b) Los trámites de información pública y audiencia. 2.1.3. Novedades en la Ley $39 / 2015$ que fortalecen la evaluación ex ante de los reglamentos: el plan anual normativo. 2.1.4. Novedades en la Ley 39/2015 que fortalecen la evaluación ex post de los reglamentos: la evaluación normativa. 2.1.5. Novedades en la Ley 39/2015 respecto a la administración sin papel. 3. Marco normativo autonómico. 4. Marco normativo en Euskadi.-V. Valoración final.-VI. Fuentes.
\end{abstract}

\section{Introducción}

El interés por hacer buenas leyes no es nuevo. Podemos encontrar en autores clásicos de la Antigüedad como Platón y Aristóteles referencias directas a la cualidad de las leyes. En los umbrales de la Edad Moderna Erasmo de Rotterdam dejó escrito: "Conviene que las leyes sean las menos posibles, que sean justísimas, que se orienten al bien común y que sean conocidas al detalle por el pueblo.»(1) El interés por la eficacia de la norma jurídica y la realidad que aspira ordenar es consustancial a la historia del pensamiento.

Todo proceso de comunicación normativa implica una serie de elementos que parten del mismo como un emisor, con competencia para dictar una norma y un receptor del mensaje normativo. Ambos operan en

(1) ASTARLOA, Ignacio (Coord.), "La preocupación por hacer buenas normas», en Técnica Normativa 2016-2017. Memento Práctico Francis Lefebvre. Madrid, 2015, pág 9. 
un contexto determinado que teniendo en cuenta la norma de la que se trate puede ser muy diverso. Según Joxerramon Bengoetxea:

La calidad en la elaboración de normas, desde esta perspectiva consiste en el hecho que este proceso de comunicación normativa sea exitoso y no se vea frustrado por distintos motivos. Un proceso exitoso es aquel en que el mensaje normativo que ha emitido el ente emisor $y$ el mensaje normativo que ha recibido el ente receptor coinciden. Si el ente receptor ha procesado la información comunicativa generando una información normativa (p.ej. sobre derechos, obligaciones, facultades, potestades, etc.) distinta a la que emitió o pretendió emitir el ente emisor, entonces se produce un fallo en la comunicación normativa. El fallo se detectará normalmente en el ente emisor por no haber emitido un mensaje normativo suficientemente claro o no haber tenido en cuenta las condiciones o el medio de emisión del mensaje. La calidad en la elaboración de las normas consiste entonces, desde esta perspectiva en el éxito del proceso de comunicación de normas. Si el ente emisor no tiene clara la norma que ha de emitir, si no plasma esa norma en un medio escrito suficientemente comprensible y claro, el proceso comunicativo se frustrará y los destinatarios no serán capaces de conocer el sentido, alcance, significado o finalidad de la norma. (2)

El proceso de comunicación normativa se efectúa teniendo en cuenta un canal determinado, como es un boletín oficial y es en este soporte donde se puede frustrar la comunicación por diversos motivos como la falta de claridad del mensaje. Pero no es solo este motivo por lo que puede fallar el proceso comunicativo. El emisor de la norma y los destinatarios deben compartir un marco cultural determinado para que la norma sea entendida por la colectividad. De igual importancia es ser consciente de que el proceso de elaboración normativa que se produce antes de la publicación de la norma implica otro proceso comunicativo de unos actores en una estructura compleja como es la de la administración pública. Este complejo proceso que implica diálogo interdepartamental, emisión de informes, dictámenes, trámites de audiencia y la celebración de reuniones de discusión y coordinación debe establecerse sobre la base de que el men-

(2) BENGOETXEA, Joxerramon, Informe JAKE, 2012, pp. 12-13. El Informe JAKE fue el resultado del Proyecto de Investigación JAKE de la UPV/EHU dirigido y coordinado por el Profesor Joxerramon Bengoetxea y compuesto por los Profesores Edorta Cobreros, Juan Ignacio Ugartemendia, Iker Nabaskues y la profesora Maite Zelaia en 2012. El Proyecto tuvo como objetivo el análisis de la calidad normativa en las disposiciones reglamentarias del Gobierno Vasco y tuvo como resultado la elaboración de un checklist a modo de cuestionario piloto y como herramienta práctica para testar la calidad normativa en dicha institución. 
saje normativo que se quiere transmitir es compartido por toda esta red de actores, porque una vez que la norma ha sido publicada el mensaje imputable al emisor de la norma es el mensaje que ha sido publicado en el boletín oficial correspondiente. De manera que si el mensaje publicado es ambiguo, impreciso o indeterminado los destinatarios pueden interpretar la norma en un sentido diferente al que pretendía el emisor de la misma.

Estos son los problemas de interpretación de los que tradicionalmente se viene ocupando la teoría y filosofía del derecho. En realidad son problemas de comunicación de los que se pueden extraer enseñanzas y conclusiones sobre el proceso de elaboración de las normas. Siguiendo a Bengoetxea podemos distinguir cinco niveles de racionalidad práctica en un proceso de comunicación normativa: (3)

- Una racionalidad comunicativa o lingüística. El emisor debe transmitir con claridad el mensaje que quiere transmitir a la ciudadanía.

- Una racionalidad jurídico-formal. La norma forma parte de un sistema jurídico complejo como el nuestro, en el que interactúan los niveles local, foral, autonómico, estatal y europeo.

- Una racionalidad pragmática o de eficacia. La conducta de los ciudadanos debe ajustarse a lo que pretende la administración pública emisora.

- Una racionalidad sociológica. La norma debe ser capaz de adaptar la realidad a los objetivos propuestos en la medida que los ciudadanos los secunden.

- Una racionalidad ética. El objetivo de la norma tiene una pretensión axiológica puesto que tiene la vocación de construir una sociedad más justa.

\section{Problemas en torno a la calidad del ordenamiento (4)}

En la actualidad podemos sintetizar algunos rasgos que caracterizan la situación actual en relación a la calidad de las normas: (5)

(3) Ibídem, p. 14.

(4) «Una de las causas de la actual inseguridad jurídica, de la opacidad de nuestros ordenamientos, es la degradación, más que de la técnica, del rigor con que deben elaborarse las disposiciones de carácter general, defecto que es una secuela casi inevitable del exceso de producción: a mayor producción, menor calidad. Esta degradación repercute en la seguridad jurídica porque no se sabe con certeza cuáles son las normas que están vigentes, porque es muy difícil localizarlas y porque, aun teniéndolas a mano, no se entienden. Actualmente, hasta para un experto profesional del Derecho es difícil señalar con certeza cuáles son las normas vigentes sobre determinada materia en un momento dado. El principio iura novit Curia ha pasado a ser una mera presunción, bastante pretenciosa por cierto, si es que alguna vez fue verídico.» RUBIO LLORENTE, Francisco, "El papel del Consejo de Estado en el control de la calidad técnica de las normas.", en Revista Española de la Función Consultiva n. ${ }^{\circ}$ 6. Julio-Diciembre 2006, p.28.

(5) Véase ASTARLOA, Ignacio (Coord.), "Los problemas del ordenamiento y la calidad de las normas», en Técnica Normativa 2016-2017. Memento Práctico Francis Lefebvre. Madrid, 2015, pp. 15-20. 
1. Se produce el fenómeno de una producción normativa extraordinaria y desmedida. La especial proliferación de normas ha llevado al fenómeno de la hipertrofia e inflación de normas de todo tipo y origen.

2. A la proliferación cuantitativa, se añade una proliferación cualitativa, constituyendo el mapa normativo actual una "mosaico» normativo de gran complejidad por la diferente vigencia y ámbito de aplicación de las normas. Hoy los tipos de normas son innumerables.

3. Las normas son cada vez más voluminosas y con un contenido poco conciso por una tendencia cada vez más creciente a la regulación de más aspectos de la realidad y a hacerlo cada vez con más detalle. En el extremo de este fenómeno hay que hacer referencia a las «normas ómnibus» que regulan multitud de materias y afectan, modifican o derogan numerosas normas anteriores. También se ha producido la aparición de un casuismo normativo como producto de una especial proliferación de "leyes a medida" y de "leyes singulares" que atentan contra la generalidad, racionalidad y orden abstracto de justicia para la ciudanía característicos del Estado de Derecho.

4. Las normas jurídicas se erigen como herramientas que pretenden dar respuesta a necesidades inaplazables, por lo que se hacen cada vez con más urgencia y en consecuencia, con menos cuidado. Se busca la rapidez lo que en ocasiones es sinónimo de improvisación. Este fenómeno es el origen de cambios normativos constantes lo que provoca que existan normas jurídicas no duraderas, contingentes o coyunturales. Estamos antes normas que se modifican constantemente como expresión del oportunismo político o económico. Todo esto provoca que las leyes sean cada vez más oscuras, incompletas, confusas, cargadas de ambigüedad y con una clara tendencia al abuso en el empleo de conceptos indeterminados.

5. Se ha producido una regresión en lo referido a la utilización del lenguaje en las normas jurídicas que hay que enmarcar en un contexto más amplio y generalizado de pérdida social colectiva del respeto a la corrección del lenguaje. Algunos juristas plantean un escenario cuando menos preocupante: reduccionismos expresivos, penetración en las leyes de modismos coloquiales, surgimiento de estribillos políticos que van introduciéndose en las leyes, uso de palabras inventadas, entre muchos otros. (6)

(6) CAZORLA PRIETO, Luis María, «El deficiente lenguaje de las leyes», en ABC, 11 de marzo de 2014. 
6. Los ordenamientos han pasado a caracterizarse por una enorme complejidad donde se pueden encontrar remisiones equivocadas, incoherencias, redundancias, inserciones de materias ajenas a la propia norma, etc. La fragmentación y dispersión son hoy el paradigma de "ordenamientos desordenados». El fenómeno de la hiperregulación convive de manera paradójica con recomendaciones del ámbito del soft law, con la desregulación, la autorregulación, los códigos éticos o los manuales de «buenas prácticas» de origen anglosajón. En este contexto se han extendido en el lenguaje jurídico enunciados programáticos o promocionales en los que los imperativos normativos son sustituidos por verbos como "promover», "pretender», «impulsar», etc.

\section{Criterios generales para afrontar la calidad de las normas}

A continuación recogemos algunas líneas de actuación eficiente en la asunción de una cultura de calidad normativa: (7)

1. Actuaciones para la mejora del ordenamiento:

1.1. Unidad y coherencia del ordenamiento:

- Respeto a la diversa tipología legislativa.

- Corrección de contenido en las Leyes de Presupuestos.

- Corregir el uso extensivo de los Decretos-Leyes.

- Aumentar la producción de Decretos Legislativos (Refundiciones).

- Reducir la producción de Reglamentos.

- Respeto escrupuloso a la reserva material de Ley.

- Simplificación de los mecanismos de trasposición de directivas.

- Evitar normas programáticas o imprecisas.

- Reducir las normas singulares.

(7) El Memento Práctico Técnica Normativa 2016-2017, Astarloa, I (Coord.), Francis Lefebvre. Madrid 2015, constituye una herramienta novedosa en lo que se refiere al panorama de la calidad normativa en el Estado. Se trata de un profundo estudio sobre la forma en la que se elaboran las normas, y cómo deberían elaborarse a la luz de los problemas actuales. En la obra se recogen los requisitos materiales y formales de la normativa aplicable en todos los niveles de la administración y se incluyen los dictámenes del Consejo de Estado y los Consejos autonómicos sobre la calidad normativa. Finalmente se plantean soluciones para aligerar la carga normativa y dotar de calidad a las normas jurídicas. Por ello me detengo en los aspectos más sustanciales, novedosos y originales de esta obra. Para un estudio más exhaustivo y pormenorizado de estos criterios, véase "Pautas generales para la correcta elaboración de las normas y la mejora del ordenamiento" que se incluyen entre las páginas 97-179. 
- Reducir la dispersión normativa.

- Realizar normas homogéneas, evitando las leyes "ómnibus».

1.2. Sostenibilidad, estabilidad y predictibilidad:

- Evitar la precipitación y la improvisación.

- Realizar agendas normativas.

- Cuidar la coordinación y el control por parte del centro gestor de la producción de la norma.

- Producir normas jurídicas con vocación de permanencia, priorizándolas sobre las normas modificativas y temporales.

1.3. Simplificación del ordenamiento:

- Reducir la legislación. Legislar solo cuando sea estrictamente necesario.

- Eliminar las regulaciones prescindibles.

- Establecer Programa de evaluación y simplificación normativa, derogando leyes obsoletas y simplificando las existentes introduciendo modificaciones.

1.4. Recurrir a la codificación para que los códigos pasen a recuperar un papel central en el sistema jurídico.

1.5. Calidad, transparencia y accesibilidad:

- Claridad y comprensión de la norma. Elaborar textos claros, comprensibles y que no estén sujetos a ambigüedad.

- Normas concisas. Reducir la presencia de conceptos complicados.

- Reducir el reenvío entre normas para aclarar el significado de los preceptos y evitar la repetición de preceptos normativos.

- Clarificar las normas aplicables a cada caso, dejando claro su ámbito de aplicación usando para ello las disposiciones complementarias.

- Aclarar el régimen de transitoriedad de las normas.

- Dejar claro qué normas están vigentes y cuáles han sido derogadas.

- Permitir el acceso de la ciudadanía al proceso de elaboración normativa.

- Sustitución del papel por la edición electrónica.

2. Actuaciones sobre la calidad de la norma:

2.1. Utilizar los manuales de directrices para la elaboración de normas.

2.2. Hacer un buen uso del lenguaje usando palabras precisas. 
2.3. Facilitar la intervención de lingüistas en la redacción de normas.

2.4. Exigir unos principios materiales a todas las normas:

- Justificación de la necesidad de su aprobación.

- Dejar claro el objetivo de la norma.

- Criterio de oportunidad.

- Definir soluciones idóneas para el objetivo.

- Valorar la proporcionalidad de la actuación normativa.

- Valorar el impacto económico.

- Valorar la expectativa de la eficacia de la norma.

- Valorar la capacidad de la administración competente para hacer efectiva la realización de la norma.

- Analizar el impacto de la norma.

3. Actuaciones sobre los procedimientos de elaboración de las normas:

- Cuidar especialmente la autoría del borrador del texto articulado inicial.

- Cuidar el diálogo fluido entre políticos y juristas en la fase previa a la tramitación.

- Dejar constancia documental de todo el proceso de elaboración de la norma.

- Elegir personas responsables directas del proceso normativo.

- Realizar las comprobaciones finales sobre el cumplimiento de todos los trámites de informes, dictámenes y trámites de audiencia.

Por todo lo dicho, la calidad de las normas hace referencia a la calidad técnica, exige rigor, claridad expositiva y sistemática y coherencia con el resto del ordenamiento jurídico (calidad técnico-formal), pero también a su contenido en la medida que la norma sea adecuada, necesaria y proporcionada para alcanzar los objetivos normativos propuestos (calidad material). Por eso, no es solo relevante la corrección técnica, el lenguaje, la coherencia de la disposición, sino también el contenido de las normas y especialmente su finalidad, esto es su capacidad de ordenar correctamente la sociedad o para ser cumplidas sin que se produzcan desajustes o consecuencias no deseadas. (8)

(8) ÁLVAREZ VÉLEZ, M. ${ }^{\text {a }}$ Isabel, "La potestad legislativa gubernamental: calidad de las normas y evaluación ex ante», en Asamblea, Revista Parlamentaria de la Asamblea de Madrid, n. ${ }^{\circ}$ 36, Junio 2017, pp. 41-42. 


\section{Normativa aplicable respecto a la calidad de las normas}

La sociedad digital y global en la que vivimos y el ordenamiento jurídico que sirve para ordenarla, está como es obvio, condicionado por los rasgos propios del Estado Social y Democrático de Derecho y el Estado de las Autonomías en nuestro caso. Las necesidades de una ciudadanía cada vez más exigente respecto a la administración pública y el servicio público ha incrementado el interés de los operadores jurídicos sobre el tema de la calidad de las normas jurídicas y la técnica legislativa. La "legística», "ciencia de la legislación» o "técnica legislativa» impulsa la convicción de que es preciso tener en consideración las normas desde su fase de elaboración e incorporación al ordenamiento. Esta disciplina desarrolla conocimientos que pueden ayudar a hacer normas más correctas y más eficaces y desarrolla métodos de evaluación de impacto y eficacia real de las normas jurídicas. (9)

Las instituciones de la Unión Europea han sido las que han promovido la cultura de la calidad normativa y se han implicado en la implementación de planes de mejora de la técnica normativa así como en la decisión de poner en funcionamiento planes de evaluación de impacto real de las normas jurídicas en la ciudadanía. (10) Hay que citar como el embrión del interés por la calidad normativa la Resolución del Consejo de las Comunidades Europeas de 8 de junio de 1993, relativa a la calidad de la redacción de la legislación comunitaria [DOCE n. ${ }^{\circ}$ c 1661/1 de 17 de junio), modificada en 1998 [DOCE n. 73 de 17 de marzo de 1999]. Unos años más tarde hay que destacar el programa "Legislar mejor» de la Comisión Europea que supuso un fuerte impulso por parte de esta institución europea en el ámbito de la calidad normativa en el año 2002 (Comunicación de la Comisión, de 5 de junio de 2002, Plan de acción "Simplificar y mejorar el marco regulador» [COM (2002) 278 final). Se trata del primer paso para simplificar y mejorar la legislación de la UE, introduciendo la obligatoriedad de las evaluaciones de impacto y las

(9) ASTARLOA, Ignacio (Coord.), Op. Cit, pág 31.

(10) De forma paralela a la labor de las instituciones de la Unión en el desarrollo de la cultura de la calidad normativa hay que hacer mención al papel desempeñado por la OCDE. En 1995, esta institución aprobó la «Recomendación para Mejora la Calidad de la Regulación Gubernamental», primera declaración internacional sobre principios regulatorios comunes a los países miembros. A esta Recomendación le siguió un "Acuerdo sobre cuestionarios de evaluación" que incluyan preguntas para guiar a los operadores jurídicos a la hora de redactar una memoria como: ¿Está definido correctamente el problema? ¿Está justificada la intervención del estado? ¿Constituye la regulación la mejor forma de intervención pública? ¿Tiene la regulación un fundamento jurídico? (entre muchas otras). Esta labor pionera de la OCDE se ha ido actualizando y se plasma en la «Recomendación del Consejo sobre Política Normativa y Gobernanza Regulatoria" de 2012. Véase http://www.oecd.org/gov/regulatory-policy/Recommendation\%20with\%20 cover\%20SP.pdf 
consultas con las partes interesadas en todas las nuevas iniciativas propuestas por la Comisión Europea. (11)

Las iniciativas de la Unión han introducido un nuevo paradigma en los procesos de producción normativa, que permite a las instituciones reflexionar con carácter previo a la adopción de las normas sobre las alternativas disponibles, los costes, los beneficios y los efectos de las distintas opciones, proporcionando elementos adicionales de juicio para la toma de decisiones políticas. En 2012 la Comisión Europea puso en marcha el Regulatory Fitness and Performance Programme [REFIT] un programa de adecuación y eficacia de la reglamentación de la Comisión que busca garantizar que la legislación de la UE aporte resultados a los ciudadanos y las empresas de manera efectiva, eficiente y con un coste mínimo y que persigue en definitiva, que la legislación de la Unión siga siendo adecuada para sus fines y proporciones los resultados para los que fue concebida por los legisladores de la Unión. (12)

\section{Marco normativo europeo a partir de 2016}

En 2015 se produce un segundo hito en el ámbito de la calidad normativa, cuando la Comisión Europea muestra la determinación de profundizar en la mejora de la legislación en el contexto del denominado Plan Juncker(13) en la Comunicación de la Comisión al Parlamento Europeo, al Consejo, al Comité Económico y Social Europeo y al Comité de las Regiones, de 19 de mayo de 2015, "Legislar mejor para obtener mejores resultados - Un programa de la UE. Simplificar y mejorar el

(11) Este plan de acción que se implementó hay que situarlo en el contexto del Libro Blanco de la Gobernanza Europea de 2001 que dedicaba una sección a la calidad de las leyes y que se concretó en el Acuerdo Institucional "Legislar Mejor" de 16 de diciembre de 2003. Véase documento El Plan "Legislar Mejor". ¿De qué se trata? Comisión Europea, 2006 en https://publications.europa.eu/es/ publication-detail/-/publication/cccc188f-0d33-4c44-8407-eddd6242d967

(12) La finalidad del REFIT es simplificar la legislación europea, eliminar cargas innecesarias y adaptar la legislación vigente, sin interferir con los objetivos políticos. El programa presta atención especial atención a las pequeñas empresas que pueden verse afectadas de manera desproporcionada por la carga administrativa en la aplicación de las normas de la UE. Las pequeñas y medianas empresas representan el 99\% de todas las empresas de la UE. El año 2015 se inició la segunda edición del programa REFIT. Véase https://ec.europa.eu/info/law/law-making-process/overview-law-making-process/evaluating-and-improving-existing-laws/reducing-burdens-and-simplifying-law/refitmaking-eu-law-simpler-and-less-costly_es

(13) El Plan de Inversiones para Europa, conocido como "Plan Juncker», es una iniciativa de la UE para incrementar las inversiones (315.000 millones) en toda la UE e impulsar el crecimiento económico a largo plazo para el periodo 2015-2018. Véase http://www.consilium.europa.eu/es/policies/ investment-plan/ 
marco regulador» [COM (2015) 215 final). (14) Fruto del trabajo conjunto de Comisión, Parlamento y Consejo es el «Acuerdo Institucional entre el Parlamento Europeo, el Consejo de la Unión Europea y la Comisión Europea sobre la mejora de la legislación» publicado en el Diario Oficial de la Unión Europea, L123, 12 de mayo de 2016. (15) Es preciso detenerse en el contenido del Acuerdo, toda vez que supone el faro que va a guiar todas las iniciativas de mejora en la legislación en adelante.

El Acuerdo institucional sobre la mejora de la legislación de 2016 en la Unión Europea

El apartado I plantea los Compromisos y objetivos comunes con los cuales las instituciones se comprometen a la mejora de la legislación, fomentando la sencillez y la claridad y la coherencia en la legislación de la Unión, así como una mayor transparencia en el procedimiento legislativo. El apartado II, plantea la Programación que incluye planes anuales y plurianuales de actuación conjunta entre las instituciones europeas firmantes del acuerdo. El apartado III del Acuerdo se introducen ya unos Instrumentos para la mejora de la Legislación entre los que destaco los siguientes:

La Evaluación de impacto. Las evaluaciones de impacto deben abordar la existencia, la magnitud y las consecuencias de un problema y valorar si es necesaria la actuación de la Unión. Deben indicar soluciones alternativas $y$, cuando sea posible, los costes y beneficios potenciales a corto y largo plazo, evaluando de forma integrada y equilibrada las repercusiones económicas, medioambientales y sociales mediante análisis cualitativos y cuantitativos. (...) Las evaluaciones de impacto también deben abordar, siempre que sea posible (...) las repercusiones en la competitividad y las cargas administrativas de las distintas opciones, prestando especial atención a las pymes (pensar primero a pequeña escala), los aspectos digitales y las consecuencias territoriales. Las evaluaciones de impacto deben estar basadas en información precisa, objetiva y completa y ser proporcionadas en lo que atañe a su alcance y a su enfoque (artículo 12 del Acuerdo).

(14) En la Comunicación, la Comisión insiste en la página 3 del documento que «la mejora de la legislación no es un ejercicio burocrático. (...) La Comisión se compromete a asumir la responsabilidad política de aplicar en su trabajo los principios y procesos de mejora de la legislación y pide a las demás instituciones de la UE y a los Estados Miembros que hagan lo mismo.» Véase https:// ec.europa.eu/transparency/regdoc/rep/172015/ES/1-2015-215-ES-F1-1.PDF

(15) https://eur-lex.europa.eu/legal-content/ES/TXT/?uri=OJ:L:2016:123:TOC 
Consultas públicas, consultas a los interesados, y tratamiento de la información recibida en el marco de dichas consultas. La Comisión, antes de la adopción de su propuesta, efectuará consultas públicas de forma abierta y transparente, garantizando que las modalidades y plazos de dichas consultas públicas, permitan una participación lo más amplia posible. En particular, la Comisión impulsará la participación directa de las pymes y otros usuarios finales en las consultas, incluidas las consultas públicas por internet. Los resultados de dichas consultas públicas y consultas a los interesados se comunicarán sin dilación a ambos colegisladores y se harán públicos (artículo 19).

Evaluación ex post de la legislación vigente. La Comisión informará al Parlamento Europeo y al Consejo de su planificación plurianual de las evaluaciones de la legislación vigente e incluirá en dicha planificación, en la medida de lo posible, sus solicitudes de evaluación en profundidad de ámbitos políticos específicos o de actos legislativos (artículo 21).

En el contexto del ciclo legislativo, las evaluaciones de la legislación y las políticas vigentes, basadas en la eficiencia, la eficacia, la pertinencia, la coherencia y el valor añadido, deben servir de base para la evaluación de impacto de otras opciones de actuación (artículo 22).

El apartado IV del Acuerdo incorpora unos Instrumentos Legislativos a desarrollar en el futuro que conviene destacar aquí:

En relación con cada propuesta normativa, la Comisión proporcionará al Parlamento Europeo y al Consejo una explicación y una justificación sobre su elección de base jurídica y tipo de acto jurídico en la exposición de motivos que acompaña a la propuesta. La Comisión debe tener debidamente en cuenta la diferencia de naturaleza y efectos que existe entre los reglamentos y las directivas. La Comisión también justificará en sus exposiciones de motivos las medidas propuestas con arreglo a los principios de subsidiariedad y de proporcionalidad, así como la compatibilidad de estas con los derechos fundamentales. Asimismo, dará cuenta del alcance y los resultados de cualquier consulta que se haya mantenido con el público y con los interesados, de la evaluación de impacto y de la evaluación ex post de la legislación vigente que haya realizado (artículo 25).

El apartado $V$ se refiere concretamente a procesos de mejora en relación a los Actos Delegados y de Ejecución:

A fin de mejorar la transparencia y las consultas, la Comisión se compromete a recabar, antes de la adopción de los actos delegados, todo el asesoramiento técnico necesario, incluso mediante la consulta a expertos de los Estados miembros y consultas públicas. Además, y cuando sea necesario un asesoramiento técnico más amplio en las fases iniciales de preparación de los proyectos de actos de ejecución, la Comisión recurrirá a grupos de expertos, consultará a los interesados específicos y llevará a cabo consultas públicas, según proceda (artículo 28). 
Las tres Instituciones se comprometen a crear en estrecha cooperación, al finalizar 2017 a más tardar, un registro conjunto funcional de actos delegados cuya información se estructure adecuadamente y sea fácil de utilizar, de modo que se refuerce la transparencia, se facilite la planificación y quede constancia de cada una de las distintas fases del ciclo de vida de los actos delegados (artículo 29).

El apartado VI expresa medidas en el campo de la Transparencia y Coordinación del Procedimiento Legislativo:

El Parlamento Europeo y el Consejo, en su calidad de colegisladores, convienen en la importancia de mantener contactos estrechos ya en una fase previa a las negociaciones interinstitucionales, con el fin de lograr una mejor comprensión de sus posiciones respectivas. Para ello, en el contexto del proceso legislativo, facilitarán el intercambio mutuo de opiniones y de información, incluso invitando periódicamente a representantes de las demás instituciones a intercambios de opiniones informales (artículo 34).

En aras de la eficacia, el Parlamento Europeo y el Consejo garantizarán una mejor sincronización de la tramitación de las propuestas legislativas. En concreto, el Parlamento Europeo y el Consejo compararán los calendarios indicativos de las diferentes fases que conduzcan a la adopción definitiva de cada propuesta legislativa (artículo 35).

En su caso, las tres Instituciones podrán convenir en coordinar sus esfuerzos para acelerar el proceso legislativo garantizando al mismo tiempo que se respeten las prerrogativas de los colegisladores y se preserve la calidad de la legislación (artículo 36).

Las tres Instituciones convienen en que facilitar información a los Parlamentos nacionales debe permitir a estos ejercer íntegramente las prerrogativas que les atribuyen los Tratados (artículo 37).

Las tres Instituciones garantizarán la transparencia de los procedimientos legislativos, sobre la base de la legislación y jurisprudencia correspondientes, $y$, en concreto, de las negociaciones trilaterales entre ellas (artículo 38).

El apartado VII en el ámbito de la Ejecución y Aplicación de la Legislación de la Unión:

Las tres Instituciones insisten en la necesidad de aplicar rápida y correctamente la legislación de la Unión en los Estados miembros. El plazo para la transposición de las directivas será lo más breve posible y, por lo general, no superará los dos años (artículo 42).

Finalmente en el apartado VIII se hace referencia a las medidas de simplificación:

Las tres Instituciones confirman su compromiso de recurrir a la técnica legislativa de la refundición para la reforma de legislación vigente con más frecuencia (artículo 46). 
Las tres Instituciones acuerdan cooperar con el fin de actualizar y simplificar la legislación y evitar un exceso de regulación y de cargas administrativas a los ciudadanos, las administraciones y las empresas, incluidas las pymes, garantizando a la vez el cumplimiento de los objetivos de la legislación (artículo 48).

\section{Marco normativo en el Estado}

En el Estado español se han ido dando pasos paulatinamente en lo que se refiere a la calidad normativa. Así, es preciso citar el Acuerdo del Consejo de Ministros de 22 de julio de 2005 que aprobó las Directrices de Técnica Normativa y que están vigentes hoy en día, así como el Real Decreto 1083/2009 de 3 de julio sobre la regulación, novedosa entonces en nuestro ordenamiento, de las memorias de análisis de impacto normativo. (16) En el mismo año se aprobó la Guía Metodológica para la elaboración de la Memoria. Estos dos documentos, la Memoria de impacto normativo y la Guía han sido decisivos en la mejora de la calidad de las normas en el Estado y han permitido asentar la evaluación ex ante de los impactos, como instrumento indispensable de la política regulatoria. (17)

En cuanto a textos más legibles y jurídicamente claros, hay que mencionar el Informe de la Comisión de Modernización del Lenguaje Jurídico elaborado por la Comisión de Expertos Modernización del Lenguaje Jurídico del Ministerio de Justicia, que integra en su seno al Director de la Real Academia de la Lengua y que merece ser tenido en consideración. (18)

Las leyes más recientes del estado que han afectado al tema que tratamos son la Ley 2/2011 de Economía Sostenible y la Ley 19/2013 de Transparencia. La Ley 2/2011 de Economía Sostenible en su Título I «Mejora del entorno económico", en su Capítulo I, relativo a la "Mejora de la calidad de la

(16) El Real Decreto 1083/2009, de 3 de julio, por el que se regula la memoria del análisis de impacto normativo, incorporó formalmente, al nivel de las instituciones centrales, el concepto de impacto, para que un único documento incluyera las memorias, estudios e informes sobre la necesidad y oportunidad de las normas proyectadas, así como la memoria económica y el informe sobre el impacto por razón de género, que debían acompañar a los anteproyectos de ley y a los proyectos de reglamento, debiendo dedicarse uno de los apartados a un análisis sobre la adecuación de la norma propuesta al orden de distribución de competencias.

(17) ÁLVAREZ VÉLEZ, Isabel., Op, cit., pág 50.

(18) La Comisión de expertos recibió el encargo de presentar al Consejo de Ministros un informe de recomendaciones sobre el lenguaje empleado por los profesionales del Derecho, con la finalidad de hacerlo más claro y comprensible para los ciudadanos. Este informe aporta recomendaciones a los profesionales y se acompaña de ejemplos prácticos que pueden ser de una gran utilidad a los creadores de normas en relación al lenguaje jurídico. 
regulación», recogió los principios de buena regulación aplicables a las iniciativas normativas y los instrumentos para la mejora regulatoria, con especial atención a la transparencia y la evaluación previa y posterior de dichas iniciativas y la formalización de instrumentos a ese fin: los nuevos informes periódicos sobre las actuaciones de mejora regulatoria y el trabajo del Comité para la Mejora de la Regulación de las Actividades de Servicios (artículos 6 y 7 de la Ley), que si bien supusieron entonces una novedad, como veremos han quedado claramente rebasados por la LPACAP de 2015.

La Ley 19/2013 de 9 de diciembre, de Transparencia, Acceso a la información pública y Buen Gobierno proporcionó novedades muy jugosas en materia de técnica normativa:

La Ley impuso a las Administraciones Públicas la obligación de hacer públicas las informaciones de relevancia jurídica, y entre ellas, los proyectos normativos (Leyes y Reglamentos).

Puso en marcha un proceso de revisión y simplificación normativa concreto que implica la participación de todos los Departamentos Ministeriales y encomendó un Plan de racionalidad y simplificación normativa, a elaborar centralizadamente por la Secretaría de Estado de Relaciones con las Cortes del Ministerio de Presidencia.

En el ámbito de la publicidad de las normas estableció la obligatoriedad de publicación de los Anteproyectos de Ley, reglamentos y los proyectos de Decretos Legislativos en el momento en que soliciten los dictámenes a los órganos consultivos correspondientes (artículo 7).

Es digno de mención por su importancia en el ámbito de la calidad de las leyes la puesta en marcha por la Ley de un proceso sistemático y generalizado de revisión y simplificación del ordenamiento estatal (Disposición Adicional Segunda). Para ello, las Secretarías Generales Técnicas de cada Departamento Ministerial Ilevan a cabo un proceso de revisión y simplificación, que en aplicación de la cooperación administrativa, pueda coordinar su actividad con los órganos competentes de las Comunidades Autónomas, en el ejercicio de las competencias que le son propias.

Se pueden mencionar otras leyes como La Ley 20/2013 de 9 de diciembre de garantía de la unidad de mercado en los procesos de colaboración normativa, que también incorporó instrumentos concretos en el ámbito de la cooperación en la elaboración de las normas (artículos 14 y 15 de la Ley); y la Ley 20/2014, de 29 de octubre, por la que se delegó en el gobierno la potestad de dictar diversos textos refundidos que era fruto del cumplimiento de las disposiciones de la OCDE sobre simplificación y ordenación normativa, comenzando un proceso de refundición de normas que si continuase de manera sistemática supondría un gran paso adelante en la calidad del ordenamiento. No obstante, es preciso detenerse específicamente en el análisis de la Ley 39/2015, con importantes y profundas novedades en relación a la calidad normativa. 
Es preciso hacer referencia por otra parte, al papel que ha desempeñado el Consejo de Estado como órgano de control de calidad de las normas. Este órgano ha sido prolífico en sugerencias y observaciones en sus memorias anuales sobre la actividad normativa del gobierno, propiciando que la normativa aprobada sea lo más clara posible. En el informe del año 2011 señaló que en ocasiones las Memorias de análisis de impacto "no son suficientemente expresivas", hay veces que "se omiten informes" o "se llevan a cabo audiencias incompletas". Esto ha llevado a algunos autores a defender que la labor consultiva del Consejo de Estado además del control formal que ejerce, al analizar la fundamentación y motivación de las opciones reguladoras, está llevando a cabo en realidad, una comprobación ex ante de la adecuación de la norma a criterios de calidad normativa, lo que ahonda finalmente en criterios de legalidad. (19)

\subsection{LA CALIDAD DE LAS NORMAS TRAS LA LEY 39/2015 LPACAP}

En el Preámbulo de la ley, se expresa que durante los más de veinte años de vigencia de la Ley 30/1992 se ha ido avanzando en la mejora de la producción normativa, en el camino de la "Better regulation" y "Smart regulation». Se define la regulación inteligente como un "marco jurídico de calidad, que permite el cumplimiento de un objetivo regulatorio a la vez que ofrece los incentivos adecuados para dinamizar la actividad económica, permite simplificar procesos y reducir cargas administrativas." (20) Sobre esta premisa, la nueva ley implica el desarrollo de nuevas disposiciones en el ámbito del análisis de impacto ex ante y ex post de las normas, una clara mejora en lo que se refiere a la sistematización de los principios de buena regulación y una profundización de la participación de los ciudadanos y empresas en los procesos de elaboración normativa.

Hay que destacar las importantes modificaciones que implica la nueva ley respecto del marco normativo en el ejercicio de la potestad reglamentaria y los trámites que debe llevar a cabo la administración antes de aprobar una disposición general, en el título VI (artículos 127 a 133). La potestad reglamentaria era un ámbito que había recibido escasa atención en nuestro ordenamiento jurídico, caracterizado, siguiendo a Irene Ara-

(19) ÁLVAREZ VÉLEZ, Isabel., Op, cit., pág 54.

(20) Con esta regulación se siguen las recomendaciones que en esta materia ha formulado la Organización para la Cooperación y el Desarrollo Económicos (OCDE) en su informe emitido en 2014 "Spain: From Administrative Reform to Continous Improvement» (Exposición de motivos de la LPACAP). 
guás, por un "exagerado esquematismo" y por un insuficiente desarrollo de la participación ciudadana consagrada en el artículo $105 \mathrm{CE}$, no correspondido con la «exigencia solemne contenida en el referido precepto constitucional.» (21) El nuevo título VI de la ley supera el marco de la Ley 2/2011 de Economía Sostenible que desarrollaba los principios de buena regulación entre los artículos 4 a 7 de la ley, que han quedado derogados por la Disposición Derogatoria única de la LPACAP.

\subsubsection{Novedades en la Ley 39/2015 que sistematizan la buena regulación en el procedimiento de elaboración de normas: los principios de buena regulación}

La inclusión del artículo 129 (22) supone un claro impulso de la better regulation, puesto que incorpora medidas dirigidas a incrementar su efectividad.

(21) ARAGUÁS, Irene., La transparencia en el ejercicio de la potestad reglamentaria. Atelier, BarceIona, 2017, pp. 40-41.

(22) El artículo 129 de la ley expresa:

1. En el ejercicio de la iniciativa legislativa y la potestad reglamentaria, las Administraciones Públicas actuarán de acuerdo con los principios de necesidad, eficacia, proporcionalidad, seguridad jurídica, transparencia, y eficiencia. En la exposición de motivos o en el preámbulo, según se trate, respectivamente, de anteproyectos de ley o de proyectos de reglamento, quedará suficientemente justificada su adecuación a dichos principios.

2. En virtud de los principios de necesidad y eficacia, la iniciativa normativa debe estar justificada por una razón de interés general, basarse en una identificación clara de los fines perseguidos y ser el instrumento más adecuado para garantizar su consecución.

3. En virtud del principio de proporcionalidad, la iniciativa que se proponga deberá contener la regulación imprescindible para atender la necesidad a cubrir con la norma, tras constatar que no existen otras medidas menos restrictivas de derechos, o que impongan menos obligaciones a los destinatarios.

4. A fin de garantizar el principio de seguridad jurídica, la iniciativa normativa se ejercerá de manera coherente con el resto del ordenamiento jurídico, nacional y de la Unión Europea, para generar un marco normativo estable, predecible, integrado, claro y de certidumbre, que facilite su conocimiento y comprensión y, en consecuencia, la actuación y toma de decisiones de las personas y empresas.

Cuando en materia de procedimiento administrativo la iniciativa normativa establezca trámites adicionales o distintos a los contemplados en esta Ley, éstos deberán ser justificados atendiendo a la singularidad de la materia o a los fines perseguidos por la propuesta.

Las habilitaciones para el desarrollo reglamentario de una ley serán conferidas, con carácter general, al Gobierno o Consejo de Gobierno respectivo. La atribución directa a los titulares de los departamentos ministeriales o de las consejerías del Gobierno, o a otros órganos dependientes o subordinados de ellos, tendrá carácter excepcional y deberá justificarse en la ley habilitante.

Las leyes podrán habilitar directamente a Autoridades Independientes u otros organismos que tengan atribuida esta potestad para aprobar normas en desarrollo o aplicación de las mismas, cuando la naturaleza de la materia así lo exija.

5. En aplicación del principio de transparencia, las Administraciones Públicas posibilitarán el acceso sencillo, universal y actualizado a la normativa en vigor y los documentos propios de 
Los principios de necesidad y eficacia (129.2) requieren que la iniciativa normativa esté «justificada por una razón de interés general, basarse en una identificación clara de los fines perseguidos y ser el instrumento más adecuado para garantizar su consecución» (129.2). La finalidad del precepto es imponer la cultura de la calidad a la administración por medio de que estudie si es necesario aprobar una norma o si por el contrario sería suficiente estudiar una mejora o incluso prescindir de medidas regulatorias. (23)

El principio de proporcionalidad impone que "la iniciativa que se proponga deberá contener la regulación imprescindible para atender la necesidad a cubrir con la norma, tras constatar que no existen otras medidas menos restrictivas de derechos, o que impongan menos obligaciones a los destinatarios" (129.3), cuestión que está directamente ligada a los principios de necesidad y eficacia puesto que el cumplimiento de estos es la condición previa a que se considere la proporcionalidad de la misma.

El principio de seguridad jurídica, que se recoge en el 129.4 tiene tres proyecciones: en primer lugar, la iniciativa normativa tiene que ser coherente con el ordenamiento jurídico estatal y de la Unión (primer párrafo). En segundo lugar, si la disposición establece trámites adicionales a los contemplados en la LPACAP, estos deben estar justificados en orden al objetivo de la propuesta normativa (segundo párrafo). En tercer lugar, se plantea con carácter excepcional la posibilidad de atribuir a los titulares de los departamentos ministeriales, consejerías u otros órganos independientes subordinados la habilitación para el desarrollo reglamentario de una ley (tercer párrafo). (24)

El principio de transparencia viene desarrollado en el 129.5 y engarza con la Ley 19/2013 de transparencia, estableciendo la necesidad de justificar las normas en su exposición de motivos y posibilitando la participación efectiva en la elaboración de las normas. Este precepto que profundiza en el conocimiento respecto a las normas aprobadas por la

su proceso de elaboración, en los términos establecidos en el artículo 7 de la Ley 19/2013, de 9 de diciembre, de transparencia, acceso a la información pública y buen gobierno; definirán claramente los objetivos de las iniciativas normativas y su justificación en el preámbulo o exposición de motivos; y posibilitarán que los potenciales destinatarios tengan una participación activa en la elaboración de las normas.

6. En aplicación del principio de eficiencia, la iniciativa normativa debe evitar cargas administrativas innecesarias o accesorias y racionalizar, en su aplicación, la gestión de los recursos públicos.

7. Cuando la iniciativa normativa afecte a los gastos o ingresos públicos presentes o futuros, se deberán cuantificar y valorar sus repercusiones y efectos, y supeditarse al cumplimiento de los principios de estabilidad presupuestaria y sostenibilidad financiera.

(23) ARAGUÁS, Irene., Op, cit., p. 244.

(24) Ibídem, p. 245. 
Administración implica el uso por primera vez de criterios propios de la publicidad activa. (25)

El principio de eficiencia (129.6) exige evitar cargas administrativas innecesarias y racionalizar la gestión de los recursos públicos. No obstante, hay que tener en cuenta que este precepto no puede suponer en ningún caso un deterioro en la protección de los interese generales, puesto que hay cargas que siguen siendo necesarias en la medida que salvaguardan derechos amparados por el ordenamiento. (26)

Finalmente, en cuanto a los principios de estabilidad presupuestaria y estabilidad financiera (129.7) se señala que la cuantificación y valoración de los efectos de la normativa debe someterse a estos principios.

Hay que destacar asimismo, que el 129.1 no se limita a enunciar los principios de buena actuación sino que exige además que la adecuación a los mismos esté plenamente justificada en los preámbulos de la correspondiente iniciativa normativa.

\subsubsection{Novedades en la Ley 39/2015 que incentivan la participación ciudadana en el procedimiento de elaboración de normas:}

\section{a) La consulta previa}

Además de incorporar la consulta previa como nuevo trámite de participación ciudadana, la nueva regulación introduce modificaciones sustanciales en los trámites de la audiencia e información pública en relación a la regulación anterior, por medio del artículo 133.(27)

(25) La publicidad activa como medio de satisfacer el derecho a conocer de los ciudadanos comporta que la Administración divulgue ciertas informaciones sin necesidad de que haya una solicitud previa por parte de los ciudadanos. Se trata de una actitud proactiva, que determina que la administración, sin una demanda expresa, ponga a disposición de los ciudadanos, información relativa a su actividad. La publicidad activa representa un paso más respecto a la publicación ya que propicia un mayor nivel de conocimiento por parte de los ciudadanos. Ibídem, p. 196.

(26) Ibídem, p. 247.

(27) El artículo 133 de la ley expresa:

1. Con carácter previo a la elaboración del proyecto o anteproyecto de ley o de reglamento, se sustanciará una consulta pública, a través del portal web de la Administración competente en la que se recabará la opinión de los sujetos y de las organizaciones más representativas potencialmente afectados por la futura norma acerca de:

a) Los problemas que se pretenden solucionar con la iniciativa.

b) La necesidad y oportunidad de su aprobación.

c) Los objetivos de la norma.

d) Las posibles soluciones alternativas regulatorias y no regulatorias.

2. Sin perjuicio de la consulta previa a la redacción del texto de la iniciativa, cuando la norma afecte a los derechos e intereses legítimos de las personas, el centro directivo competente publicará el texto en el portal web correspondiente, con el objeto de dar audiencia a los ciu- 
La consulta previa (133.1) es un trámite participativo distinto de la audiencia y de la información pública. Sus destinatarios son los «sujetos y organizaciones representativas potencialmente afectados». No es un trámite circunscrito solo a los interesados como ocurre con el trámite de audiencia y tampoco se abre a todos los ciudadanos como ocurre con el trámite de información pública. Es de destacar el momento procedimental en el que se realiza la consulta previa, que es antes de elaborar el proyecto de reglamento, cuestión que le diferencia respecto a los trámites de audiencia e información, que se llevan a cabo justamente en el momento anterior a la aprobación del reglamento. El objeto de la consulta previa es recabar la opinión sobre la conveniencia de la norma, algo que no tendría sentido en los trámites de audiencia e información puesto que en el momento que suceden, prácticamente la norma ha seguido toda su tramitación. La forma en que se desarrolla la consulta previa es a través del portal web de la administración. En cuanto al su carácter preceptivo, en principio es obligatorio, aunque no se sitúa al nivel de la audiencia y la información pública pues se podrá omitir su realización en los supuestos que se considere que la propuesta normativa no tiene un impacto significativo en la actividad económica (133.4). (28)

\section{b) Los trámites de información pública y de audiencia}

La principal diferencia entre ellos es que tienen diferentes destinatarios. La audiencia se dirige a los ciudadanos afectados (133.2) y la elec-

dadanos afectados y recabar cuantas aportaciones adicionales puedan hacerse por otras personas o entidades. Asimismo, podrá también recabarse directamente la opinión de las organizaciones o asociaciones reconocidas por ley que agrupen o representen a las personas cuyos derechos o intereses legítimos se vieren afectados por la norma y cuyos fines guarden relación directa con su objeto.

3. La consulta, audiencia e información públicas reguladas en este artículo deberán realizarse de forma tal que los potenciales destinatarios de la norma y quienes realicen aportaciones sobre ella tengan la posibilidad de emitir su opinión, para lo cual deberán ponerse a su disposición los documentos necesarios, que serán claros, concisos y reunir toda la información precisa para poder pronunciarse sobre la materia.

4. Podrá prescindirse de los trámites de consulta, audiencia e información públicas previstos en este artículo en el caso de normas presupuestarias u organizativas de la Administración General del Estado, la Administración autonómica, la Administración local o de las organizaciones dependientes o vinculadas a éstas, o cuando concurran razones graves de interés público que lo justifiquen.

Cuando la propuesta normativa no tenga un impacto significativo en la actividad económica, no imponga obligaciones relevantes a los destinatarios o regule aspectos parciales de una materia, podrá omitirse la consulta pública regulada en el apartado primero. Si la normativa reguladora del ejercicio de la iniciativa legislativa o de la potestad reglamentaria por una Administración prevé la tramitación urgente de estos procedimientos, la eventual excepción del trámite por esta circunstancia se ajustará a lo previsto en aquella.

(28) ARAGUÁS, Irene., Op, cit., p. 51. 
ción sobre si este trámite se lleva a cabo por los ciudadanos o por las asociaciones que les represente no es una elección el órgano que abría este trámite, sino que ahora, los ciudadanos tienen la posibilidad de participar de manera directa. El trámite de información pública tiene en cambio como destinatarios a las demás personas por las que se puede recabar cuantas aportaciones adicionales puedan hacerse. Ambos trámites tienen carácter preceptivo y con anterioridad a la nueva LPACAP, solamente el trámite de audiencia era el obligatorio, la información pública tenía carácter potestativo. Respeto al momento procedimental en el que tienen que llevarse a cabo, a diferencia de la consulta previa, la audiencia y la información tienen sentido una vez se ha elaborado el proyecto normativo, lo que permite que las aportaciones lo sean en relación a un texto coincidente con el que se va a aprobar. Respecto a la forma, al igual que el de consulta previa será a partir del portal web que posibilitará que quienes vayan a emitir su opinión lo hagan con unas garantías de información de calidad (133.3). Respecto a su preceptividad, el artículo 133.4 sitúa ambos trámites en un mismo nivel, indicando que solo podrá prescindirse de ellos en los casos de normas presupuestarias u organizativas o cuando concurran razones de grave interés público que lo justifiquen. (29)

\subsubsection{Novedades en la Ley 39/2015 que fortalecen la evaluación ex ante de los reglamentos: el plan anual normativo}

Una de las críticas más importantes que merecía el ejercicio de la potestad reglamentaria con anterioridad a la aprobación de la LPACAP era la deficiente ordenación de las actuaciones previas a la elaboración de un reglamento. (30) Este ámbito ha sido desarrollado ahora por el artículo 132 que hace mención al Plan Normativo: (31)

El plan normativo conlleva efectos positivos que es preciso destacar. En primer lugar, otorga un mayor rigor a la planificación de la actividad normativa propiciando una mayor congruencia y coherencia en la intervención de la administración pública. De forma que frena una «impulsivi-

(29) Ibídem, p.65.

(30) Ibídem, p.48.

(31) El artículo 132 de la ley expresa:

1. Anualmente, las Administraciones Públicas harán público un Plan Normativo que contendrá las iniciativas legales o reglamentarias que vayan a ser elevadas para su aprobación en el año siguiente

2. Una vez aprobado, el Plan Anual Normativo se publicará en el Portal de la Transparencia de la Administración Pública correspondiente. 
dad" que en ocasiones lleva a aquella a aprobar reglamentos ad hoc y con una base fáctica inconsistente. Por otra parte el plan normativo va a permitir dar a conocer a los ciudadanos las normas que se aprobarán en un determinado lapso de tiempo, lo que redunda en beneficio de la seguridad jurídica. (32)

\subsubsection{Novedades en la Ley $39 / 2015$ que fortalecen la evaluación ex post de los reglamentos: la evaluación normativa(33)}

Con la evaluación normativa se realiza una comprobación acerca de si se han conseguido los objetivos previstos y si los costes y cargas de la regulación están justificados. Se trata de un instrumento válido para detectar normas ineficaces. De forma que la evaluación normativa se configura como el colofón final de la intervención administrativa. En cuanto a la forma en que se produce esta, la evaluación se llevará a cabo de forma periódica y se plasmará en un informe que tendrá carácter público. (34)

\subsubsection{Novedades en la Ley 39/2015 respecto a la administración sin papel}

Uno de los retos de la ley es lograr implantar una «administración sin papel», interconectada por medio del uso generalizado de medios electrónicos. El uso de los medios electrónicos deja de ser algo excepcional y la gestión electrónica de todos los procedimientos se convierte en obligatoria. Se simplifican los medios electrónicos y se generaliza la presentación de documentos a través de un registro electrónico general, por cada administración, que funcionará como un portal que facilitará el acceso a los registros electrónicos de cada organismo y su correspondiente archivo electrónico.

(32) ARAGUÁS, Irene., Op, cit., pp.49-50

(33) El artículo 130 de la ley expresa:

1. Las Administraciones Públicas revisarán periódicamente su normativa vigente para adaptarla a los principios de buena regulación y para comprobar la medida en que las normas en vigor han conseguido los objetivos previstos y si estaba justificado y correctamente cuantificado el coste y las cargas impuestas en ellas.

El resultado de la evaluación se plasmará en un informe que se hará público, con el detalle, periodicidad y por el órgano que determine la normativa reguladora de la Administración correspondiente.

2. Las Administraciones Públicas promoverán la aplicación de los principios de buena regulación y cooperarán para promocionar el análisis económico en la elaboración de las normas y، en particular, para evitar la introducción de restricciones injustificadas o desproporcionadas a la actividad económica.

(34) Ibídem, p. 76. 
En el preámbulo de la ley se expresa que a pesar de que la Ley 30/1992 fue consciente del impacto de las nuevas tecnologías, la Ley 11/2007 de acceso electrónico de los ciudadanos a los Servicios Públicos fue la que propició el salto definitivo hacia la administración electrónica y la que dio carta de naturaleza legal al derecho de los ciudadanos a relacionarse electrónicamente con la administración pública. La nueva LPACAP apuesta por el funcionamiento íntegramente electrónico, impulsa los principios de eficacia y eficiencia, ahorra costes a ciudadanos y empresas y propicia una administración pública más ágil.

De esta forma, los Títulos IV y $\mathrm{V}$ de la ley, relativos a la instrucción del procedimiento y finalización del mismo, contienen preceptos que estipuIan el uso generalizado y obligatorio de medios electrónicos en las fases de iniciación, ordenación, instrucción y finalización del procedimiento. A su vez, se incorpora la regulación del expediente administrativo estableciendo su formato electrónico y los documentos que deben integrarlo. (35)

\section{Marco normativo autonómico}

En estos últimos años, sobre todo como consecuencia de la aprobación de la Ley 19/2013 de Transparencia se han producido algunas iniciativas normativas que tienen el objetivo de profundizar en la calidad de las normas.

En Cataluña la Ley 26/2010, de 3 de agosto, de régimen jurídico y de procedimiento de las administraciones públicas de Cataluña; en concreto su título IV relativo al Procedimiento de elaboración de disposiciones reglamentarias (artículos 59-70), ya había constituido una novedad en la profundización de la cultura de la buena regulación. En el desarrollo de la ley catalana tuvo una gran incidencia la creación de una Dirección de calidad normativa encargada de impulsar la calidad de las normas en Cataluña. Esta Dirección elaboró una Guía de Buenas prácticas en el mismo año 2010. Junto a estos organismos la Comisión Jurídica Asesora de la Generalitat ha jugado un papel importante en este ámbito.

(35) Así, el artículo 70.2 de la ley establece que:

Los expedientes tendrán formato electrónico y se formarán mediante la agregación ordenada de cuantos documentos, pruebas, dictámenes, informes, acuerdos, notificaciones y demás diligencias deban integrarlos, así como un índice numerado de todos los documentos que contenga cuando se remita. Asimismo, deberá constar en el expediente copia electrónica certificada de la resolución adoptada.

Y respecto a la resolución que ponga fin al procedimiento administrativo, el artículo 88.4 expresa:

Sin perjuicio de la forma y lugar señalados por el interesado para la práctica de las notificaciones, la resolución del procedimiento se dictará electrónicamente y garantizará la identidad del órgano competente, así como la autenticidad e integridad del documento que se formalice mediante el empleo de alguno de los instrumentos previstos en esta Ley. 
Más recientemente y tras la aprobación de la Ley 19/2013, la Ley 19/2014 de transparencia, acceso a la información pública y buen gobierno de Cataluña desarrolla un título de la misma, el Título V, al Buen Gobierno. El Capítulo III de la ley está dedicado a la «Mejora de la calidad normativa" (artículos 62-64). En estos artículos se expresa que "la administración debe ejercer una iniciativa normativa que sea previsible, estable y fácil de comprender para los ciudadanos", que las «iniciativas normativas deben referirse a sectores materiales homogéneos, y deben ser claras y coherentes" (artículo 62). También se expresa que "la administración debe llevar la iniciativa legislativa de forma que la aprobación de una norma conlleve una simplificación del ordenamiento jurídico", así como que debe "facilitar el conocimiento del derecho vigente" (artículo 63). O que la administración «debe promover pruebas piloto previas a la aprobación de nuevas medidas reguladoras" (artículo 64).

En la Comunidad Valenciana, hay que reseñar la Ley 2/2015, de 2 de abril, de la Generalitat, de Transparencia, Buen Gobierno y Participación Ciudadana. En dicha ley se puede destacar el Titulo I, que regula la transparencia en la gestión de la actividad pública, el título IV, dedicado al régimen de garantías del sistema de transparencia, acceso a la información pública y buen gobierno y el título $\mathrm{V}$ que regula los aspectos relativos a la participación ciudadana. Asimismo hay que señalar el Acuerdo de 25 de marzo de 2015, del Pleno de Las Cortes valencianas, por el que se aprueba la reforma del Reglamento de Las Cortes, que supone un hito en el desarrollo de instrumentos de participación ciudadana en la comunidad, y que articula la posibilidad de presentar enmiendas de participación ciudadana a los proyectos de ley que se encuentren en tramitación parlamentaria. (36)

En Islas Baleares hay que señalar la Ley 5/2015, de 23 de marzo, de racionalización y simplificación del ordenamiento legal y reglamentario de la Comunidad Autónoma. La finalidad de la ley balear es mejorar el ordenamiento, simplificar la profusión de normas existentes y facilitar el acceso de ciudadanos y operadores jurídicos a un ordenamiento formado por versiones vigentes y alude en su articulado a instrumentos como la derogación expresa de normas obsoletas o en desuso, la autorización al gobierno autonómico para aprobar textos refundidos y encomienda al gobierno para que elabore versiones consolidadas de las normas reglamentarias que se han ido modificando.

En otras Comunidades se han elaborado Directrices de Técnica Normativa como en el caso de Aragón -Orden de 31 de mayo de 2013, del Con-

(36) GUILLEM CARRAU, Javier, "Las enmiendas de participación ciudadana: su inserción en el procedimiento legislativo ordinario de Les Corts Valencianes", en Asamblea, Revista Parlamentaria de la Asamblea de Madrid, n. ${ }^{\circ}$ 36, Junio 2017. 
sejero de Presidencia y Justicia, por la que se publican las Directrices de Técnica Normativa del Gobierno de Aragón-; en Galicia en 2014 -Resolución de 5 de noviembre de 2014, de la Dirección General de la Asesoría Jurídica General, por la que se ordena la publicación del Acuerdo del Consello de la Xunta de Galicia de 30 de octubre de 2014, por el que se aprueban las Directrices de técnica normativa. En Galicia es preciso reseñar que se ha legislado sobre la implementación de la participación ciudadana en el mismo ámbito que el apuntado en la Comunidad Valenciana, con la Ley $7 / 2015$, de 7 de agosto, de iniciativa legislativa popular y participación ciudadana en el Parlamento de Galicia. En este mismo sentido en Andalucía la Reforma del Reglamento del Parlamento aprobada el 26 de noviembre de 2014, reguló las enmiendas ciudadanas en los proyectos de ley.

\section{Marco normativo en Euskadi}

En Euskadi, en materia de elaboración de normas, está vigente la Ley $8 / 2003$, de 22 de diciembre que regula el procedimiento de elaboración de disposiciones de carácter general. La ley 8/2003 incluyó en la categoría de disposiciones de carácter general tanto las iniciativas parlamentarias como los anteproyectos de ley, que reciben un tratamiento unitario en esta norma. Esta fue una de las aportaciones más relevantes de la ley vasca. Que la Comunidad Autónoma Vasca disponga de una normativa específica relativa al procedimiento de elaboración de las normas, denota la importancia que se atribuye en Euskadi a esta cuestión.

Hay que tener en cuenta también la Ley 10/1982, de 24 de noviembre, básica de normalización del uso del Euskera (artículo 8) aplicable teniendo en cuenta nuestro régimen cooficial y teniendo en consideración que el hecho de tener que redactar las normas jurídicos en dos lenguas, puede dar lugar a problemas que alcanzan a la calidad normativa.

Asimismo están la Orden de 6 de abril de 1993 por el que se publica el Acuerdo de Consejo de Gobierno de 23 de marzo de 1993 sobre directrices para la elaboración de proyectos de Ley, Decretos, Órdenes y Resoluciones., El Acuerdo de Consejo de Gobierno de 9 de febrero de 2010, por el que se aprueban Instrucciones de tramitación en el procedimiento de elaboración de disposiciones de carácter general con rango de Decreto y otras medidas encaminadas a su ordenación; el Acuerdo de Consejo de Gobierno de 10 de enero de 1995, por el que se aprueban las Instrucciones sobre normas provisionales de tramitación de Asuntos ante el Consejo de Gobierno y la Resolución de 5/2007, de 14 de febrero sobre Evaluación Previa de Impacto en Función del Género (artículos 19-20 de la Ley $4 / 2005$, de 18 de febrero, para la Igualdad de Mujeres y Hombres). 
En el ámbito autonómico vasco no se pueden dejar sin mencionar las aportaciones de la Comisión Jurídica Asesora de Euskadi (COJUA), en cuyas memorias anuales se contienen, sintetizadas, interesantes consideraciones, tanto sobre la eficacia como sobre la técnica de las normas de nuestra Comunidad Autónoma sometidas a su control. Finalmente es preciso mencionar el documento Ilamado «Modelo de Tramitación de disposiciones de carácter general con rango de Decretos", elaborado por la Dirección de Innovación y Administración Electrónica del Departamento de Justicia y Administración Pública del Gobierno Vasco.

Este panorama normativo, aún en vigor en Euskadi, va a sufrir una profunda transformación, por lo que parece más interesante atisbar siquiera la orientación que van a seguir las nuevas leyes vascas, más que detenernos en el análisis de las que están en vigor. De hecho, las primeras medidas que tocan aspectos de la calidad de las leyes, vienen de manos del Decreto 128/2016, de 13 de septiembre, de la Comisión Vasca de Acceso a la Información Pública. Este decreto desarrolla en el ámbito de la Comunidad Autónoma de Euskadi el esquema operativo esencial de la Ley 19/2013 de Transparencia, en cuanto a la disponibilidad de un órgano específico para el control de la transparencia y, en particular, para conocer de las reclamaciones que, con carácter potestativo y previo a la jurisdicción contencioso-administrativa, se interpongan frente a toda resolución denegatoria, en materia de acceso por la ciudadanía a la información pública, dictada por las Administraciones públicas vascas.

De un alcance de mayor calado son dos proyectos normativos que están en fase de tramitación. En primer lugar el Proyecto de ley de Transparencia, Participación Ciudadana y Buen Gobierno del Sector Público Vasco que va a establecer los principios generales que guiarán el funcionamiento del sector público en relación a una "buena administración" tal y como se formula en la Carta de Derechos Fundamentales de la Unión Europea. (37)

No hay duda que la ley se presenta como un instrumento para reforzar la transparencia, la publicidad, la participación ciudadana en el diseño de las políticas públicas, la evaluación de las mismas y el buen gobierno. Como novedades del texto, se pueden anticipar temas que se recogen expresamente, y que a la espera de cuál sea su redacción y aprobación

(37) En la Exposición de motivos del proyecto en tramitación se expresa:

El presente texto en particular busca instar al debate resolutivo en Euskadi sobre la mejora de la percepción de la ciudadanía respecto a la llamada cosa pública, su revalorización, contribuyendo a crear, en definitiva, una nueva cultura administrativa basada en los nuevos paradigmas que requieren los tiempos actuales, relacionados con los diversos aspectos de lo que se ha venido a llamar la buena gobernanza, abordada desde el triángulo conceptual que conforman la evaluación de políticas públicas, la transparencia y la participación de la ciudadanía en los asuntos públicos, partiendo de la premisa de que ninguno puede funcionar o sostenerse por sí solo, sin los otros dos. 
definitiva, nos pueden orientar sobre el carácter coherente de la ley con el nuevo contexto de impulso de la calidad normativa que implican las Leyes 19/2013 y 39/2015: se recoge el «derecho a una buena administración", se contemplan medidas de publicación activa, de simplificación normativa, evaluaciones ex ante y ex post, destacando las evaluaciones de impacto de las políticas públicas, medidas de fomento de planificación normativa, calidad de la información, información institucional, procesos participativos, la creación de un registro de la participación ciudadana o la creación de una plataforma de gobierno abierto.

En segundo lugar, hay que hacer referencia al Proyecto de ley de modificación de la ley de procedimiento de elaboración de las disposiciones de carácter general. Toda vez que en el contexto de renovación y modernización normativa que hemos venido comentando obliga a una adaptación obligada de la Ley vasca 8/2003 a los criterios mucho más desarrollados y actualizados de la administración inteligente y que una vez que la Ley 39/2015 ha entrado en vigor, su actualización parece evidente.

\section{Valoración final}

El ámbito de la calidad de las normas es un ámbito relativamente novedoso. Es necesario profundizar a partir del estudio de casos prácticos para poder testar así, donde se falla en lo que se refiere a la calidad normativa y donde se llevan a la práctica y resultan exitosas buenas prácticas en el ámbito de la técnica normativa. En todo caso parece claro que la fase en la que la calidad de las leyes era un campo donde nos limitábamos a recoger las buenas prácticas en el extranjero, para posteriormente tratar de implementarlas en nuestro entorno, ha finalizado. El nuevo impulso de la calidad ha tomado forma en los diferentes niveles de la administración pública, lo que permitirá en los años próximos, extraer conclusiones firmes sobre los procesos de elaboración de las normas, y sobre todo tipo de mejoras en el ámbito de la participación ciudadana o en la mejora de redacción de las leyes.

Las últimas novedades que se han producido en el ámbito de la calidad normativa, en el espacio de la Unión Europea, dibujan un escenario de fuerte impulso de la cultura de la calidad en las instituciones comunitarias, que merece ser tenido en consideración, y exigen asimismo una toma de conciencia por parte de los legisladores respecto a su papel en el proceso de simplificación y claridad normativa y respecto a su papel activo en la solución a la hiperinflación normativa que hemos señalado en este artículo.

El impulso por la calidad de las normas tiene un reflejo muy claro y profundo en el caso del ordenamiento del Estado. La Ley 19/2013 marcó 
un camino que se ha visto consolidado de manera rotunda con la Ley 39/2015. En esta ley hay una clara incentivación y refuerzo de la participación ciudadana en el procedimiento de elaboración de normas, que si bien es cierto ya estaba recogido en el artículo 105 de la CE, el título VI de la nueva ley logra su materialización en el proceso normativo. La regulación de las actuaciones previas al ejercicio de la potestad reglamentaria es un paso muy positivo puesto que es el instrumento que puede contribuir de manera significativa a evitar normas innecesarias en la lucha contra la hiperinflación normativa. Asimismo puede ayudar a evitar normas que no cumplen unos estándares mínimos de calidad. La incorporación de los principios de buena regulación y la evaluación ex post implican la materialización de la cultura de la calidad normativa en nuestro ordenamiento.

En el contexto de Euskadi entramos en una nueva fase en el ámbito de la calidad de las normas, toda vez que la regulación contenida en la Ley 8/2003 debe adaptarse a la nueva coyuntura. Habrá que estudiar cuales son los avances que contienen los textos definitivos de las nuevas leyes sobre transparencia, participación ciudadana y buen gobierno y la que regulará las disposiciones de carácter general en el ámbito de la Comunidad Autónoma de Euskadi respectivamente, para valorarlas en el contexto de la profundización en la cultura de la calidad normativa de la normativa estatal.

\section{Fuentes}

ALONSO GARCÍA, R., Sistema jurídico de la Unión Europea (2. ${ }^{a}$ ed.), Civitas/Thomson, Madrid, 2010.

ÁLVAREZ VÉLEZ, M. ${ }^{a}$ Isabel, "La potestad legislativa gubernamental: calidad de las normas y evaluación ex ante», en Asamblea, Revista Parlamentaria de la Asamblea de Madrid, n. ${ }^{\circ}$ 36, Junio 2017.

ARAGUÁS, Irene, La transparencia en el ejercicio de la potestad reglamentaria. Atelier, Barcelona, 2017.

ASTARLOA, Ignacio (coord.). Técnica normativa 2016-2017. Francis Lefebvre, 2015, Madrid.

ATIENZA, Manuel, "Sociología Jurídica y Ciencia de la Legislación», en R. Bergali (coord.) El Derecho y sus Realidades. Investigación y Enseñanza de la Sociología Jurídica, 1989.

ATIENZA, Manuel, Contribución a una teoría de la legislación. Editorial Civitas, Madrid, 1997.

BEITIA, Iñaki, «El procedimiento de elaboración de disposiciones generales: balance de una década de la Comisión Jurídica Asesora y nuevas aproximaciones", en RVAP núm. 85, 2009, Oñati. 
BENGOETXEA, Joxerramon, "Multilingual and Multicultural Legal Reasoning: The European Court of Justice», en Kjaer, A.L.; Adamo, S. (eds), Linguistic Diversity and European Democracy, Ashgate, 2011.

CAZORLA PRIETO, Luis María, "El deficiente lenguaje de las leyes», en $A B C, 11$ de Marzo de 2014.

CORDECH Pablo Salvador, «Técnica legislativa y teorías de la regulación», en Indret. Working paper n. ${ }^{\circ}$ 28. Barcelona. Abril de 2004.

FIGUEROA, Alberto. (coord.), "La Evaluación del Derecho», en Los Procesos de Implementación de las Normas Jurídicas. IVAP, Oñati 1993.

GARCÍA-ESCUDERO MÁRQUEZ, P., "Técnica legislativa y seguridad jurídica: ¿hacia el control constitucional de la calidad de las leyes?», en Cuadernos Civitas, Madrid, 2010.

GUICHOT, E., Transparencia y acceso a la información pública en España, Fundación Alternativas, Madrid, 2011;

GUICHOT, E., Publicidad y privacidad de la información administrativa. Civitas, Madrid, 2009.

GUILLEM CARRAU, Javier, "Las enmiendas de participación ciudadana: su inserción en el procedimiento legislativo ordinario de Les Corts Valencianes", en Asamblea, Revista Parlamentaria de la Asamblea de Madrid, n. ${ }^{\circ}$ 36, Junio 2017.

LÓPEZ I CASASNOVAS, Guillem, "La eficiencia de las normas: El análisis coste beneficio corno instrumento metodológico" en FIGUEROA LARAUDOGOITIA (coordinador), Los procesos de Implementación de las Normas. Instituto Vasco de Administración Pública, 1995.

MARCOS, Francisco, "Calidad de las normas y estudios de impacto normativo en España: dificultades y primeras experiencias», en Working Paper, IE Law School, Madrid, 2009.

MIR PUIGPELAT, Oriol, "El procedimiento de elaboración de reglamentos y Better Regulation» en Comentarios a la Ley 26/2010 de 3 de agosto de régimen jurídico y de procedimiento de las administraciones públicas de Cataluña. lustel, Madrid, 2012.

RUBIO Llorente, Francisco, «El papel del Consejo de Estado en el control de calidad técnica de las normas", en Revista Española de la Función Consultiva $n .^{\circ} 6$ (julio-diciembre 2006).

SAINZ MORENO Fernando, "Antecedentes necesarios para pronunciarse sobre un proyecto de ley", en La Calidad de las Leyes. fd. Parlamento Vasco, Vitoria-Gasteiz, 1988.

SANTAOLALLA, Fernando, "Nota acerca de las Directrices sobre la Forma y Estructura de los Anteproyectos de Ley", en Revista de las Cortes Generales, 1992. 


\section{Documentos}

COMUNICACIÓN DE LA COMISIÓN EUROPEA GOBERNANZA EUROPEA: Legislar Mejor, 27-5-02, Com (2002) 275 final.

COMUNICACIÓN DE LA COMISIÓN EUROPEA, NORMATIVA INTELIGENTE EN LA UNIÓN EUROPEA, Bruselas, 8.10.2010 COM(2010) 543 final. HOUSE OF LORDS SELECT COMMITTEE REPORT, Better Regulation, 2005.

INFORME JAKE. Grupo de Investigación EHU-UPV. 2012.

MINISTERIO JUSTICIA. Manual de estilo del Lenguaje Administrativo Ministerio para las Administraciones Públicas, Madrid, 1990 
LABURPENA: Ordenamenduko arau juridikoen kalitatea eta eraginkortasuna, gaur gaurkoz, gaurkotasun handiko gaia da. XXI. mendetik aurrera batez ere, urrats garrantzitsuak eman dira, bai gure ordenamenduko arauen hiperinflazioa berriro definitzeko arloa nabarmenduz, bai eraginkortasuna probatzeko tresnez hornituz administrazioa. Egungo araudiaren kalitatearen egoerari buruzko hausnarketa egitea da artikulu honen xedea. Lehenik eta behin, ordenamenduaren kalitatearen inguruko arazoen inguruan hausnartzen da, eta, bigarrenik, arauen kalitateari aurre egiteko irizpide orokorrei buruz. Europar Batasuneko erakundeek bultzada eman diote araudiaren kalitateari, 2016tik aurrera batez ere, eta gaurkotasuna baldintzatu du bultzada berri horrek. Bestalde, eta eremu estatalari dagokionez, Gardentasunari buruzko 19/2013 Legeak ekarri zuen urratsak baldintzatu du gaurkotasuna, baina, batez ere, Administrazio Prozedurari buruzko 39/2015 Legeak hainbat eremutan (erregulazio ona, herritarren parte-hartzea, araudiaren ex ante eta ex post ebaluazioak eta administrazio elektronikoa egonkortzeko apustua) egiten duen sakontasunak baldintzatu du. Eremu autonomikoan, estatuko legeen zentzua jasotzen duten lege berriak ari dira sortzen. Azkenik, Euskal Autonomia Erkidegoari dagokionez, bi lege-proiekturekin batera ari da bultzatzen araudiaren kalitatea: gardentasunari, herritarren parte-hartzeari eta gobernu onari buruzko lege-proiektuarekin eta EAEko Administrazio Publikoan kalitate arautzailearen kultura-sustapenean erreferenteak izango diren xedapen orokorrei buruzko lege-proiektuarekin.

GAKO HITZAK: Araudiaren kalitatea. Araudiaren teknika. Arauak egitea. 39/2015 Legea.

RESUMEN: La calidad y eficacia de las normas jurídicas del ordenamiento es hoy, un tema de rabiosa actualidad. Sobre todo a partir del siglo XXI se han dado importantes pasos que ponen el acento en redefinir la hiperinflación de normas en nuestro ordenamiento y dotar a la administración de herramientas para testar su eficacia. El propósito de este artículo es realizar una reflexión acerca del panorama de la calidad normativa en la actualidad. En primer lugar reflexionando sobre los problemas en torno a la calidad del ordenamiento así como sobre los criterios generales para afrontar la calidad de las normas. La actualidad viene, en primer lugar, condicionada por un nuevo impulso de la calidad normativa por parte de las instituciones de la Unión Europea, sobre todo a partir de 2016. En segundo lugar, y en lo que respecta al ámbito estatal, por el paso que implicó la Ley 19/2013 de Transparencia y sobre todo por la profundización que hace la Ley 39/2015 del Procedimiento administrativo en ámbitos como la buena regulación, la participación ciudadana, las evaluaciones ex ante y ex post de la normativa y su apuesta por la consolidación de la administración electrónica. En el ámbito autonómico están proliferando nuevas leyes que recogen el sentido de las leyes del Estado. Por último, en lo que respecta a Euskadi, este panorama de nuevo impulso de la calidad normativa viene de la mano de dos proyectos de ley vasca: el Proyecto de ley sobre transparencia, participación ciudadana y buen gobierno y el Proyecto de ley sobre las disposiciones de carácter general que constituirán el referente del impulso de la cultura de la calidad normativa en la administración pública vasca en el futuro. 
PALABRAS CLAVE: Calidad normativa. Técnica normativa. Elaboración de normas. Ley 39/2015.

ABSTRACT: The quality and efficiency of legal norms in the legal system is currently a cutting edge issue. Mainly from the century XXI, important steps have been taken in order to point out the redefinition of hyperinflation of norms in our legal order and to provide the administration with tools to check their efficiency. The purpose of this article is to have an in-depth discussion concerning the panorama of the normative quality at the moment. Firstly, by reflecting about the problems around the quality of the legal order and the general criteria to confront the quality of the norms. The reality is in the first place determined by the fresh impetus to normative quality on the part of EU institutions, specially from 2016. Secondly, regarding state scope, it is determined by the improvement operated by Act 19/2013 on Transparency and mainly by the deepening made by Act 39/2015 on Administrative Procedure in fields such as good regulation, citizen participation, ex ante and ex post normative assessment and its commitment for the reinforcement of electronic administration. At the regional level, new acts are proliferating that address the scope of the State legislation. Finally, as far as Euskadi is concerned, this new panorama for strengthening the normative goes hand in hand with two Basque bills: the bill on transparency and good governance and the bill about general provisions which will serve as a reference point for strengthening the culture for normative quality within the Basque public administration in the future.

KEYWORDS: Normative quality. Normative technique. Elaboration of norms. Act 39/2015. 